\title{
Economic and environmental analysis of a hybrid solar, wind and pumped storage hydroelectric energy source: a Polish perspective
}

\author{
J. JURASZ* and J. MIKULIK \\ AGH University of Science and Technology, 30 Adama Mickiewicza Ave., 30-059 Kraków, Poland
}

\begin{abstract}
This paper introduces a mixed integer non-linear mathematical model for a simulation of a hybrid energy source consisting of photovoltaics (PV), wind turbines (WT) and pumped storage hydroelectricity (PSH). The concept of PV-WT-PSH has been well described and evaluated for sparsely populated or remote areas such as islands. Here, due to the rapid development of renewable energy sources and most importantly the variable (non-dispatchable) energy sources such as wind and solar, the idea of wind and solar powered PSHs has been investigated in the context of the national energy system. The economic and environmental impact of the proposed hybrid has been assessed. The results reveal that to cover almost $40 \%$ of the energy demand one should expect the energy cost to increase by $25 \%$.
\end{abstract}

Key words: hybrid power source, mathematical modelling, variability, environmental impact.

\section{Introduction}

Over the recent years Poland has followed the global trends and systematically enriched its coal dominated energy portfolio with renewable energy sources (RES) - mainly wind and biomass $[1,2]$. This change, transformation (or, as one might even say, return) to the use of distributed energy sources which was known at the beginning of the era of electricity is driven mainly by an increasing awareness of the human causes of climate change [3], decreases in renewable energy costs [4], increases in RES performance [5], and the imposition of $\mathrm{CO}_{2}$ emission limits [6] (which are especially acute for countries with energy system based on combusting peat, lignite, hard coal or (shale) oil).

The structure of current energy markets implies that their supply side will adjust to the changing and variable (albeit predictable [7]) demand. The introduction of non-dispatchable generation in the form of solar and wind energy sources leads to a situation in which the supply side also starts to vary and this in turn leads to disruptions on the energy market. Numerous papers has been dedicated to the problem of subjugating variable renewable energy sources (VRES) and easing their integration into the energy system by means of: wind speed $[8,9]$ and irradiation $[10,11]$ forecasting, spatial and temporal complementarity of selected energy sources $[12,13]$, hybrid energy sources [14-15], energy storage options [16, 17], and demand side management [18]. Delucci and Jacobson [19, 20] state that by combining all the approaches described above and employing additional ones it is possible to cover the world energy demand using solar, wind and hydropower.

Long before the advent of the RES era in national power systems, they gained popularity in remote areas such as islands.

*e-mail: jakubkamiljurasz@gmail.com

Manuscript submitted 2016-12-20, revised 2017-04-20, initially accepted for publication 2017-05-15, published in December 2017.
Due to the usually limited natural resources available for island communities and the need to transport goods (such as oil or coal) from the continent (which increases their cost) and often very favorable solar and wind conditions, RES could easily compete economically with conventional power sources. But one would have to overcome the same problems which we face nowadays with the integration of RES, namely, their variable and non-dispatchable nature. As has already been mentioned, several approaches [8-20] can be applied, but the concept which incorporates at least three of them is a hybrid of photovoltaic (solar power), wind turbine and pumped storage hydroelectricity (PV-WT-PSH).

Coupled wind and solar power sources tend to exhibit lower variability and it is well known that on an annual time scale they exhibit a strong complementarity [11, 12, 21-24]. The concept of the temporal complementarity of a dual energy source can be explained by means of two sine functions which depict their variation in energy output; in the case of perfect temporal complementarity they will be out of phase with each other by $\pi / 2$, or in other words they have a very strong $(-1)$ negative correlation. However, perfect complementarity is very unlikely, and on a shorter time scale (days, hours) it is almost non-existent. In consequence, periods will occur with no energy available from either wind or solar generation. The opposite may occur when both sources simultaneously generate energy at their nameplate capacity. In general, the ambitious goal of meeting demand purely using VRES would require the whole system to be oversized, which will intrinsically lead to significant energy surpluses.

Therefore there arises a need to somehow transfer the energy in time, meaning that surpluses occurring in period $t$ might be used in period $t+x$. This can be done by means of energy storage. The most mature (and practically the only) bulk energy storage technology is PSH, which uses the elevation difference between an upper and a lower reservoir to store excess energy and release it when the generation from WT and PV is not sufficient to cover demand. It is important to note that in the 
current form of energy systems, PSH projects were usually used in combination with nuclear power plants or to balance the difference between diurnal and nocturnal differences in energy demand and thereby reduce the need to ramp up and ramp down conventional power plants.

The concept of wind and/or solar powered pumped storage hydroelectricity has been thoroughly investigated by many researchers and various aspects of their operation have been considered. References [25-27] analyzed the concept of wind powered PSH for the Greek island of Lesbos highlighting that most Greek islands have an unstable power grid connection to the mainland, meaning that their power systems must be autonomous. The authors state that using PSH can increase the WT contribution to coverage of energy demand. Reference [28] consider another two Greek islands (Karpathos and Kasos) where they indicate that, according to Greek law, a WT-PSH hybrid operates as a conventional power plant, i.e. it can operate on the power market. The authors of the present paper investigated the concept of wind powered PSH in the Polish context in papers [29, 30], introducing a strategy for WT-PSH operation and indicating several potential locations for new PSH projects.

Reference [31] was a theoretical study of various energy storing technologies cooperating with wind generation in Victoria State in Australia. Another continental study has been conducted for Denmark [32], where wind generation plays a crucial role in covering energy demand - in the present paper authors pointed to the fact that wind speed variation on a short time scale does not have a meaningful impact on PSH operation. References [33-35] analyzed the PV-TW-PSH hybrid from the tech- nical and economical perspective in the case of Greek islands and an island located near Hong Kong. Results indicate that wind and solar power energy sources can be a reliable and cost effective energy source. The aforementioned papers show that the use of wind- and solar-powered PSH energy sources as part of the national energy system is a promising research direction. The combination of non-dispatchable WT and PV generation with an energy storage device in the form of PSH may not only be a reliable energy source but may also significantly reduce the environmental impact of an energy generation system.

The remainder of this paper is organized as follows: the next section briefly describes the concept of the PV-WT-PSH hybrid operating as part of the national power system; the third section introduces the mathematical model enabling simulation of PV-WT-PSH operation and determining the energy flow; the fourth section summarizes the input data and assumptions made; Section 4 investigates the obtained results, while Section 5 summarizes the conducted research and states future research directions.

\section{Problem description}

The PV-WT-PSH hybrid has two passive, uncontrollable energy sources (wind and solar generation) and an energy storing part which in some situations generates electricity by releasing energy previously stored in an upper reservoir and in others uses excess energy from PV and WT to power pumps, to store energy as water potential energy, as shown in Fig. 1.

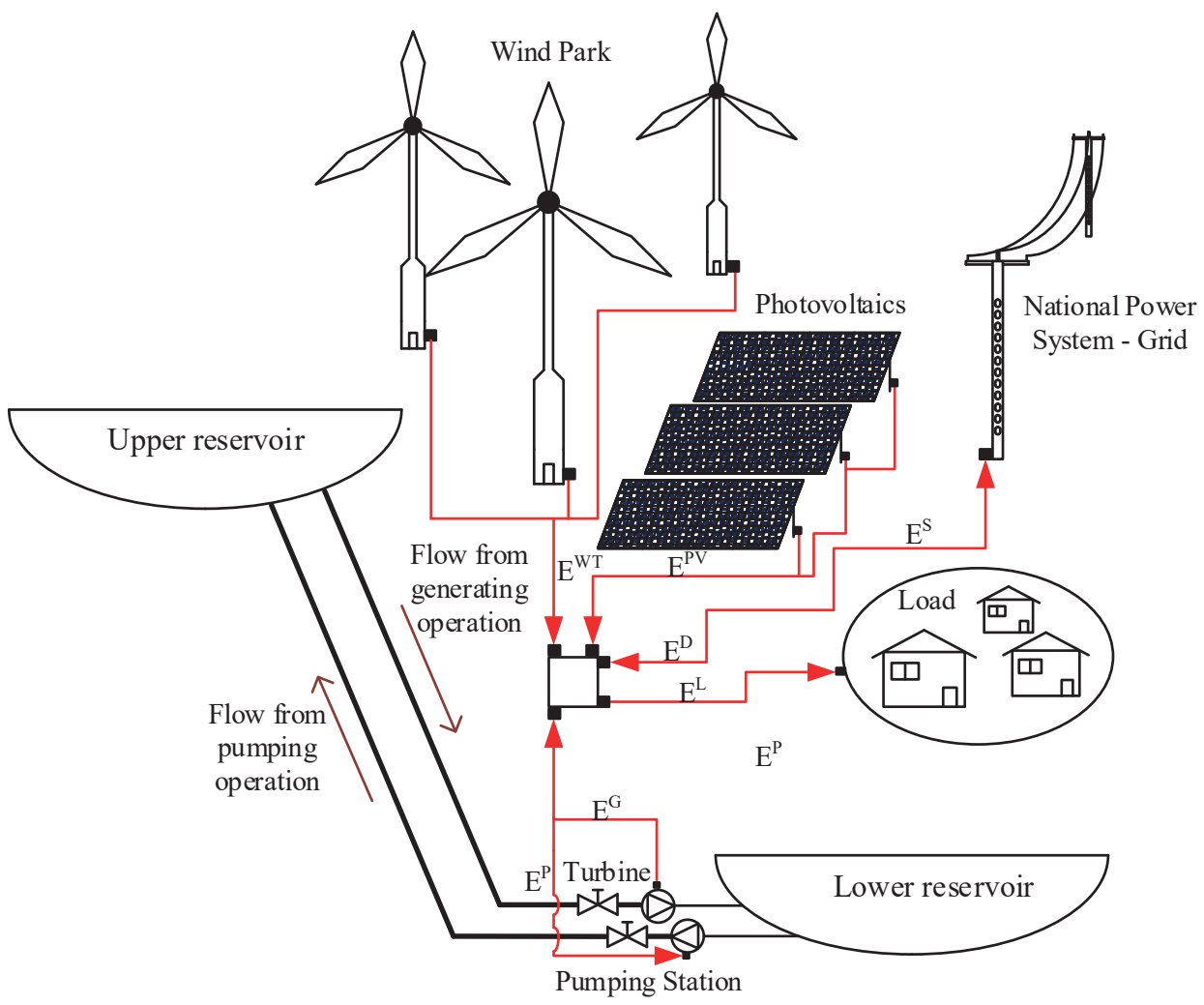

Fig. 1. Conceptual design of a PV-WT-PSH hybrid energy source operating as a part of the National Power System 
Figurte 1 depicts not only the structure of a PV-WT-PSH energy source and the possible energy flow directions within the source but also between it, the load and the National Power System (NPS). One must bear in mind that the load can be defined as an assembly of households, manufacturing and service facilities, as well as any combination of them. They will naturally exhibit various annual, weekly and daily energy demand patterns and will therefore affect the operation of the hybrid energy source. Please also note that there is a possible energy flow from and to the NPS. This may be the case when the PV-WT-PSH is not operating as an autonomous energy source. However, unpredictable energy flow from or to the PV-WT-PSH will lead to a disruption in the NPS due to the sudden change in its supply or demand side. Therefore, minimization of the energy exchange between the PV-WT-PSH and the NPS is often one of the objective functions or constraints considered whilst searching for the optimal configuration of the hybrid energy source.

The role of energy storage in a VRES hybrid energy source is irreplaceable. However, the relation between the energy demand and energy generation patterns from e.g. PV will also strongly affect the structure of the system and the energy flow. It has been found that on an hourly basis solar generation to some extent exhibits a positive correlation with energy demand in Poland [36], and PV energy yield may also smooth the midday demand peak [37]. What is more, in future PV energy sources may play an important role in the NPS by covering the increasing energy demand from rising summer temperatures and the corresponding need for air-conditioning [38]. The situations described above may decrease the need for energy storage but it will still be necessary, due to the occurrence of weather conditions critical to RES [39, 40].

In this paper an assumption has been made that PV-WT-PSH will be operating as part of the Polish NPS with its typical $\mathrm{CO}_{2}$ per kWh of electricity generated and typical cost per kWh of energy delivered to consumers. The main objective was to formulate a mixed integer mathematical model which will enable a simulation and analysis of the aforementioned hybrid energy source's operation. What is more, based on the calculations conducted it will be possible to assess the environmental impact of the proposed energy source and to compare its energy generation costs with those in the Polish energy market. The formulation of the optimization problem is presented in the next section.

\section{Mathematical model}

The energy yield from the PV system can be calculated based on (1), namely

$$
E_{i, j}^{P V}=\frac{H_{i, j} P^{P V} \eta^{P V}}{G^{S T C}},
$$

where $E_{i, j}^{P V}$ - energy yield from PV system [kWh], $H_{i, j}$ - irradiation value $[\mathrm{kWh} / \mathrm{m} 2], P^{P V}-$ installed capacity in PV system [kW], $\eta^{P V}$ - performance ratio [\%], $G^{S T C}$ - irradiance in standard testing conditions $[\mathrm{kW} / \mathrm{m} 2]$.
Meanwhile, the energy generated by a selected wind turbine can be estimated based on following formula (2)

$$
E_{i, j}^{W T}=\left\{\begin{array}{l}
0 \text { for } v_{i, j} \in\left(0, v_{1}\right) \cup\left(v_{3},+\infty\right) \\
n P^{T W} t \text { for } v_{i, j} \in<v_{2}, v_{3}> \\
n f\left(v_{i, j}\right) t \text { otherwise }
\end{array}\right.
$$

where $E_{i, j}^{W T}$ - energy yield from wind turbine [kWh], $v_{i, j}$ - wind speed $[\mathrm{m} / \mathrm{s}], v_{1}$ - wind speed at which WT starts to generate electricity $[\mathrm{m} / \mathrm{s}], v_{2}-$ wind speed at which WT operates with its nominal capacity $[\mathrm{m} / \mathrm{s}], v_{3}$ - wind speed at which due to the safety of WT its operation must be brought to a halt $[\mathrm{m} / \mathrm{s}], n$ - number of wind turbines [-], $P^{T W}$ - nominal capacity of WT [kW], $t$ - time [1 hour], $f\left(v_{i, j}\right)$ - polynomial approximating WT power output for wind speed ranging from $v_{2}$ to $v_{3}$ [kW].

The energy flow in the hybrid energy source and the remaining components (load, NPS) are determined based on the relation between its supply (PV and WT generation) and demand (load). When the supply is greater than demand, energy surplus occurs and can be stored in the upper reservoir, or has to be sent to the NPS if the PSH storage capacity is not sufficient. On the other side, when demand is greater than supply, an energy deficit occurs and it must be covered by energy previously stored in the PSH or by energy from the grid. Naturally, there is an additional factor which determines the energy flow, which is the maximal generating and storing throughput of the PSH turbines/pumps. In order to determine the volume of energy stored in the upper reservoir one must first determine the sign of the relation between supply and demand, by means of the following formula (3)

$$
E_{i, j}^{D 1}=E_{i, j}^{P V}+E_{i, j}^{W T}-E_{i, j}^{D}
$$

where $E_{i, j}^{D 1}$ - modified energy demand [kWh], $E_{i, j}^{P V}$ - energy yield from PV installation [kWh], $E_{i, j}^{W T}$ - energy yield from wind generation $[\mathrm{kWh}], E_{i, j}^{D}$ - energy demand [kWh].

Based on the above calculated modified energy demand one can determine the volume of energy stored in the upper reservoir based on formulas (4 and 5)

$$
x_{i, j}^{I}=\left\{\begin{array}{l}
1 \text { for } E_{i, j}^{D 1}>0 \\
0 \text { otherwise }
\end{array},\right.
$$

where $x_{i, j}^{I}$ - binary variable $(0,1), E_{i, j}^{D 1}$ - modified energy demand.

$$
\begin{aligned}
V_{i, j} & =\min \left(\min \left(E_{i, j}^{D 1} \eta^{P} ; P\right)+V_{i, j-1} ; V^{M}\right) x_{i, j}^{I}+ \\
& =\max \left(\min \left(\left|E_{i, j}^{D 1}\right| \frac{1}{\eta^{G}} ; G\right)+V_{i, j-1} ; 0\right)\left(1-x_{i, j}^{I}\right),
\end{aligned}
$$

where $V_{i, j} V_{i, j}$ - energy stored in upper reservoir [kWh], $\eta^{P}-$ efficiency of PSH pumps [\%], $P$ - maximal pumping throughput of PSH [kWh], $V^{M}$ - maximal storing capacity of PSH [kWh], $v_{i, j}$ - binary variable $(0,1), \eta^{G}$ - generating efficiency of PSH turbines [\%], $G$ - maximal generating throughput of $\mathrm{PSH}$ [kWh]. 
Having estimated the volume of energy stored in the upper reservoir one can determine the contribution of the individual energy source in covering the energy demand based on (6-10), namely

$$
E_{i, j}^{D-P V}=E_{i, j}^{D} \frac{E_{i, j}^{P V}}{E_{i, j}^{P V}+E_{i, j}^{W T}} x_{i, j}^{I}+E_{i, j}^{P V}\left(1-x_{i, j}^{I}\right),
$$

where $E_{i, \bar{j}}^{D_{-} P V}$ - volume of energy from PV used to cover demand [kWh], $E_{i, j}^{D}$ - energy demand [kWh], $E_{i, j}^{P V}$ - energy yield from PV system [kWh], $E_{i, j}^{W T}$ - energy yield from WT [kWh], $x_{i, j}^{I}$ - binary variable $(0,1)$.

$$
E_{i, j}^{D-W T}=E_{i, j}^{D} \frac{E_{i, j}^{W T}}{E_{i, j}^{P V}+E_{i, j}^{W T}} x_{i, j}^{I}+E_{i, j}^{W T}\left(1-x_{i, j}^{I}\right),
$$

where $E_{i, \bar{j}}^{D-W T}$ - volume of energy from WT used to cover demand [kWh], $E_{i, j}^{D}$ - energy demand [kWh], $E_{i, j}^{P V}$ - energy yield from PV system [kWh], $E_{i, j}^{W T}$ - energy yield from WT [kWh], $x_{i, j}^{I}$ - binary variable $(0,1)$.

$$
E_{i, j}^{D_{-} P S H}=\left(1-x_{i, j}^{I}\right) \min \left(\left|E_{i, j}^{D 1}\right| ; V_{i, j-1} \eta^{G} ; G\right),
$$

where $E_{i, \bar{j}}^{D P S H}$ - energy demand covered from the PSH [kWh], $E_{i, j}^{D 1}$ - modified energy demand [kWh], $V_{i, j-1}$ - volume of the energy stored in the upper reservoir $[\mathrm{kWh}], \eta^{G}$ - generating efficiency of PSH [\%], $G$ - maximal generating throughput of PSH $[\mathrm{kWh}], x_{i, j}^{I I}-$ binary variable $(0,1)$.

$$
E_{i, j}^{D_{-} E S}=\left|\min \left(E_{i, j}^{D 1}+E_{i, j}^{D_{-} P S H} ; 0\right)\right|,
$$

where $E_{i, \bar{j}}^{D_{-}} E S$ - energy demand covered from NPS [kWh], $E_{i, \bar{j}}^{D_{-}} P S H$ - energy demand covered from PSH [kWh], $E_{i, j}^{D}$ - modified energy demand [kWh].

In some situations (when maximal PSH storage capacity has been reached or pump throughput is insufficient) energy surpluses may occur from either PV or WT, or both sources. Such energy resulting from lack of storing ability will be sent to the grid, and its volume can be calculated based on $(10,11)$

$$
\begin{aligned}
E_{i, j}^{S_{-} P V}= & \left(E_{i, j}^{P V}-E_{i, j}^{D_{-} P V}\right) \min \left(V^{M}-V_{i, j-1} ; P ;\right. \\
& \left.E_{i, j}^{P V}-E_{i, j}^{D_{-} P V}\right) x_{i, j}^{I},
\end{aligned}
$$

where $E_{i, j}^{S} P V$ - energy surplus from PV generation [kWh], $E_{i, j}^{P V}$ - energy yield from PV installation $[\mathrm{kWh}], E_{i, j}^{D_{-} P V}$ - energy demand covered from PV [kWh], $V^{M}$ - maximal storing capacity of PSH [kWh], $V_{i, j-1}$ - energy stored in PSH [kWh], $\eta^{P}$ - pumping efficiency of PSH [\%], $P$ - maximal pumping throughput of PSH $[\mathrm{kWh}], x_{i, j}^{I}-$ binary variable $[0,1]$.

$$
\begin{aligned}
E_{i, j}^{S \_W T}= & \left(E_{i, j}^{W T}-E_{i, j}^{D-W T}\right) \min \left(V^{M}-V_{i, j-1} ; \frac{1}{\eta^{P}} ;\right. \\
& \left.P ; E_{i, j}^{W T}-E_{i, j}^{D_{-} W T}\right) x_{i, j}^{I},
\end{aligned}
$$

where $E_{i, j}^{S W T}$ - energy surplus from WT generation [kWh], $E_{i, j}^{W T}$ - energy yield from WT installation $[\mathrm{kWh}], E_{i, j}^{D-W T}$ - energy demand covered from PV $[\mathrm{kWh}], V^{M}$ - maximal storing ca- pacity of PSH [kWh], $V_{i, j-1}$ - energy stored in PSH [kWh], $\eta^{P}$ - pumping efficiency of PSH [\%], $P$ - maximal pumping throughput of PSH $[\mathrm{kWh}], x_{i, j}^{I}-$ binary variable $[0,1]$.

Energy generation from renewable energy sources does not occur without a negative impact on the environment. The most commonly used metric to assess a given source's impact on the environment is the emission of $\mathrm{CO}_{2}$ per generated $\mathrm{kWh}$ of energy. Table 1 summarizes the emissions considered in this study.

Table 1

Emissions of $\mathrm{CO}_{2}$ per $\mathrm{kWh}$ of generated electricity

\begin{tabular}{|l|c|}
\hline Energy source & Emissions $\left[\mathbf{k g}_{\mathbf{C O}_{2}} \mathbf{~} \mathbf{k W h}\right]$ \\
\hline Polish Energy Sector & $0.810[42]$ \\
\hline PV & $0.048[43]$ \\
\hline WT & $0.011[44]$ \\
\hline PSH - Construction & $35.7[45]$ \\
\hline PSH - Operation & $0.0018[45]$ \\
\hline
\end{tabular}

Knowing the emissions of the specific energy sources it is possible to determine the environmental impact of the proposed PV-WT-PSH hybrid operation. In this study the assumption has been made that the usual life of the PSH project is 40 years and that emissions in the construction phase will therefore be divided by 40 . Based on the following formula (12) one can determine the emissions which will originate over the considered period

$$
\begin{aligned}
E E & =\sum_{i=1}^{n} \sum_{j=1}^{m}\left(E_{i, j}^{P V} I^{P V}+E_{i, j}^{W T} I^{W T}+E_{i, j}^{D \_E S} I^{E S}+\right. \\
& \left.+E_{i, j}^{D \_P S H} I^{P S H \_2}\right)+\left(V^{M} I^{P S H \_1}\right) / 40,
\end{aligned}
$$

where $E E$ - environmental impact $\left[\mathrm{kg}_{\mathrm{CO}_{2}}\right], E_{i, j}^{P V}$ - energy yield from PV system [kWh], $I^{P V}$ - emissions resulting from PV generation $\left[\mathrm{kg}_{\mathrm{CO}_{2}} / \mathrm{kWh}\right], E_{i, j}^{W T}$ - energy yield from WTs [kWh], $I^{W T}$ - emissions from WT generation $\left[\mathrm{kg}_{\mathrm{CO}_{2}} / \mathrm{kWh}\right], E_{i, j}^{D-E S}$ - energy demand covered from NPS [kWh], $I^{E S}$ - energy system specific emissions $\left[\mathrm{kg}_{\mathrm{CO}_{2}} / \mathrm{kWh}\right], E_{i, j}^{D_{-} E S}$ - energy demand covered from NPS [kWh], $I^{P S H \_2}$ - PSH emissions resulting from operation $\left[\mathrm{kg}_{\mathrm{CO}_{2}} / \mathrm{kWh}\right], V^{M}-$ maximal storing capacity of PSH $[\mathrm{kWh}], I^{P S H_{-} 1}-\mathrm{PSH}$ emissions resulting from construction $\left[\mathrm{kg}_{\mathrm{CO}_{2}} / \mathrm{kWh}\right]$.

Similar calculations as in (12) can be performed to determine the cost of generating a unit of energy from a PV-WTPSH energy source coupled with the NPS. This can be done based on formula (13) and data from Table 2.

Table 2

Cost of electricity - Levelized Cost of Electricity (LCOE)

\begin{tabular}{|l|c|}
\hline Energy source & Emissions [€/kWh] \\
\hline Polish Energy Sector & 0.142 (Households), 0.086 (Industry) [46] \\
\hline LCOE - PV & Min: 0.079, Mean: 0.1, Max: 0.115 [47] \\
\hline LCOE - WT & Min: 0.049, Mean: 0.08, Max: 0.1025 [47] \\
\hline PSH - Construction & $2000[€ / \mathrm{kW}], 14[€ / \mathrm{kWh}][48,49]$ \\
\hline PSH - O\&M & $3[€ / \mathrm{kWh}][49]$ \\
\hline
\end{tabular}




$$
\begin{aligned}
E C & =\sum_{i=1}^{n} \sum_{j=1}^{m}\left(E_{i, j}^{P V} C^{P V}+E_{i, j}^{W T} C^{W T}+\right. \\
& \left.+E_{i, j}^{D_{-} E S} C^{E S}+E_{i, j}^{D \_P S H} C^{P S H_{-} O M}\right)+ \\
& +\left(G C^{P S H_{-} P \& G}+V^{M} C^{P S H_{-} V}\right) / 40 / \sum_{i=1}^{n} \sum_{j=1}^{m} E_{i, j}^{D}
\end{aligned}
$$

where $E C$ - energy cost $[€ / \mathrm{kWh}], E_{i, j}^{P V}$ - energy yield from PV system $[\mathrm{kWh}], C^{P V}$ - energy cost from PV $[€ / \mathrm{kWh}], E_{i, j}^{W T}-$ energy yield from WT $[\mathrm{kWh}], C^{W T}$ - energy cost from WT generation $[€ / \mathrm{kWh}], E_{i, \bar{j}}^{D_{-} E S}$ - energy demand covered by NPS [kWh], $C^{E S}$ - energy cost from NPS [€/kWh], $E_{i, j}^{D-P S H}$ - energy demand covered by PSH $[\mathrm{kWh}], C^{P S H_{-} O M}-$ operation and maintenance costs of PSH [€/kWh], $G$ - generating capacity of PSH [kWh], $C^{P S H_{-} P \& G}-$ cost of generating and pumping capacities of $\mathrm{PSH}[€ / \mathrm{kWh}], V^{M}$ - storage capacity of upper reservoir [kWh], $C^{P S H_{-} V}-$ cost of PSH storage capacity $[€ / \mathrm{kWh}], E_{i, j}^{D}-$ energy demand $[\mathrm{kWh}]$.

3.1. Optimization. The optimization problem can be formulated as follows: given is a PSH station with a priori known storage capacity $\left(\boldsymbol{V}^{\boldsymbol{M}}\right)$ and pumping/generating $(P / G)$ potential. The goal is to cover the energy needs $\left(\boldsymbol{E}_{\boldsymbol{i}, \boldsymbol{j}}^{\boldsymbol{D}}\right)$ of the selected group of customers by changing the installed capacity in PV $\left(\boldsymbol{P}^{P V}\right)$ and WT $(n)$ and finding the optimal PV-WT-PSH hybrid configuration which will lead to minimal $\mathrm{CO}_{2}$ emissions whilst satisfying imposed constraints. So the mathematical formulation of the presented problem is as follows: minimize emissions calculated by (12) subject to the constraint

$$
\sum_{i=1}^{n} \sum_{j=1}^{m}\left(E_{i, j}^{S_{-} P V}+E_{i, j}^{S_{-} W T}\right) \leq \gamma,
$$

where $E_{i, j}^{S_{-} P V}$ - energy surplus from PV installation [kWh], $E_{i, j}^{S_{-} W T}$ - energy yield from WT [kWh], $\gamma$ - maximal acceptable volume of energy surpluses, and also subject to the constraint

$$
\frac{E C}{C^{E S}} \leq \delta
$$

where $E C$ - energy cost from modified energy system (using PV-WT-PSH) [€/kWh], $C^{E S}$ - energy cost from National Power System $[€ / \mathrm{kWh}], \delta-$ acceptable ratio between both costs [-].

3.2. Scenarios and assumptions. In this study scenarios considering various storing capacities of the upper reservoir, acceptable price increase, energy from the NPS cost (households, industry: see Table 2) has been considered.

- In the case of the upper reservoir a capacity corresponding to $6 \mathrm{~h}, 12 \mathrm{~h}$ and $24 \mathrm{~h}$ of average hourly energy demand has been used.

- Energy cost resulting from the introduction of a new hybrid energy source (PV-WT-PSH) will not be: greater (15) than $\delta=1.00 ; 1.25 ; 1.50 ; 1.75$. Respectively, this translates to the assumption that the price will: not increase; increase by $\max .25 \%$; $\max .50 \%$; $\max .75 \%$.

- The pumping/generating potential in each scenario will be double, equal to and half the maximal hourly observed demand.
- Energy surpluses of zero from PV or WT generation are accepted $(\gamma=0)$.

Table 3 summarizes the parameters used in this study.

Table 3

Values of parameters used

\begin{tabular}{|c|c|c|c|}
\hline Param & Value & Param & Value \\
\hline$V^{M}$ & $\begin{array}{c}455.5 ; 227.75 ; 113.875 \\
{[\mathrm{MWh}]}\end{array}$ & $G / P$ & $\begin{array}{c}52 ; 26 ; 13 \\
{[\mathrm{MWh}]}\end{array}$ \\
\hline$I^{P V}$ & $0.048\left[\mathrm{kgCO}_{2} / \mathrm{kWh}\right]$ & $\eta^{P, G}$ & $90 \%$ \\
\hline$I^{W T}$ & $0.011\left[\mathrm{kgCO}_{2} / \mathrm{kWh}\right]$ & $C^{P V}$ & $0.1[€ / \mathrm{kWh}]$ \\
\hline$I^{E S}$ & $0.810\left[\mathrm{kgCO}_{2} / \mathrm{kWh}\right]$ & $C^{W T}$ & $0.08[€ / \mathrm{kWh}]$ \\
\hline$I^{P S H_{-} 1}$ & $35.7\left[\mathrm{kgCO}_{2} / \mathrm{kWh}\right]$ & $C^{E S}$ & $0.142[€ / \mathrm{kWh}]$ \\
\hline$I^{P S H_{-} 2}$ & $0.810\left[\mathrm{kgCO}_{2} / \mathrm{kWh}\right]$ & $C^{E S}$ & $0.086[€ / \mathrm{kWh}]$ \\
\hline$\eta^{P V}$ & $80[\%]$ & $C^{P S H_{-} V}$ & $14[€ / \mathrm{kWh}]$ \\
\hline$C^{P S H_{-} P \& G}$ & $2000[€ / \mathrm{kWh}]$ & $C^{P S H_{-} O M}$ & $3[€ / \mathrm{kWh}]$ \\
\hline$f\left(v_{i, j}\right)^{1}$ & $-0.146 \mathrm{v}^{4}+3.011 \mathrm{v}^{3}-1.486 \mathrm{v}^{2}-35.717 \mathrm{v}+83.138$ \\
\hline
\end{tabular}

${ }^{1}$ Polynomial describing Vestas V90 power curve.

3.3. Input data. Besides the data presented in Table 3 this study considered hourly irradiation [51], wind speed [52] and energy demand [53] time series for 2013-2015. The specific demand patterns for the city of Warsaw were used, whereas wind speed and irradiation parameters were taken from a location near IMGW-NRI (http://www.imgw.pl/) meteorological station in Płock.

The mean annual energy demand over the investigated threeyear period amounted to $150 \mathrm{GWh}$ - which roughly translates to 67,000 households. What is more, the calculations performed indicate that in the location in question the mean energy yield per $\mathrm{kW}$ of installed capacity in PV and WT is, respectively, 933.7 kWh and $1711.9 \mathrm{kWh}$, which translates to capacity factors of $10.7 \%$ and $19.5 \%$, which are representative for this part of Poland. This means that in order to cover the total annual energy demand (considering an idealized situation where energy generation perfectly follows demand) one would have to install $160 \mathrm{MW}$ in PV or $87 \mathrm{MW}$ in WT.

3.4. Methods. The presented mathematical models were implemented in MS Excel 2013 and the optimization problems were solved using an in-built Solver using a generalized reduced gradient (GRG) method with default settings and maximal calculations time set to 3600 CPU seconds. Problems were solved on a Dell Alienware laptop with Intel Core X920 running at $2.0 \mathrm{GHz}$ and with $16 \mathrm{~GB}$ RAM.

\section{Results and discussion}

As has been already described, calculations were conducted for 72 various scenarios, of which the first half considered energy prices from the national power system offered to households, while the second half considered those common in the industry 
sector. In each scenario it was assumed that it is possible to use an existing PSH facility with a priori known characteristics, but that neither its construction or operating costs will be neglected, nor will the environmental aspects (emissions). Table 4 summarizes the obtained results, namely: installed capacity in PV and wind turbines; participation of RES in covering energy demand, emissions reduction, shown as a ratio of emissions observed whilst using the PV-WT-PSH hybrid to emissions in the benchmark scenario (i.e. current $\mathrm{CO}_{2}$ emissions in the Polish energy sector per kWh); mean volume of energy stored in the upper reservoir as well as its maximal value; the structure of overall cost divided into individual costs. Please note that the RES participation in covering also includes the energy generated by the PSH - however, in Poland energy derived from PSHs is not currently considered to be so-called green energy, but this is due to the fact that in Poland energy which can be stored in the upper reservoir comes from coal burning plants.

At the beginning of results analysis the authors would like to justify the assumption that PSH facilities have fixed characteristics. Including two additional variables (generating/pumping and upper reservoir capacity) would make the optimization model more difficult to calculate, although this would not be a serious problem for modern computing power. However, it is not an issue of problem complexity but of the reality of PSH projects, whose characteristics are determined by local conditions (elevation difference between lower and upper reservoir; maximal upper reservoir volume). Therefore, the structure (installed capacity) of PV-WT-PSH projects will depend heavily on the fixed characteristics of existing PSHs.

The objective function which was to minimize the environmental impact of the proposed hybrid energy source had two main constraints. The first assumed that no energy surpluses from either PV or WT generation will occur over the considered period $(\gamma=0)$. The second guaranteed that the energy

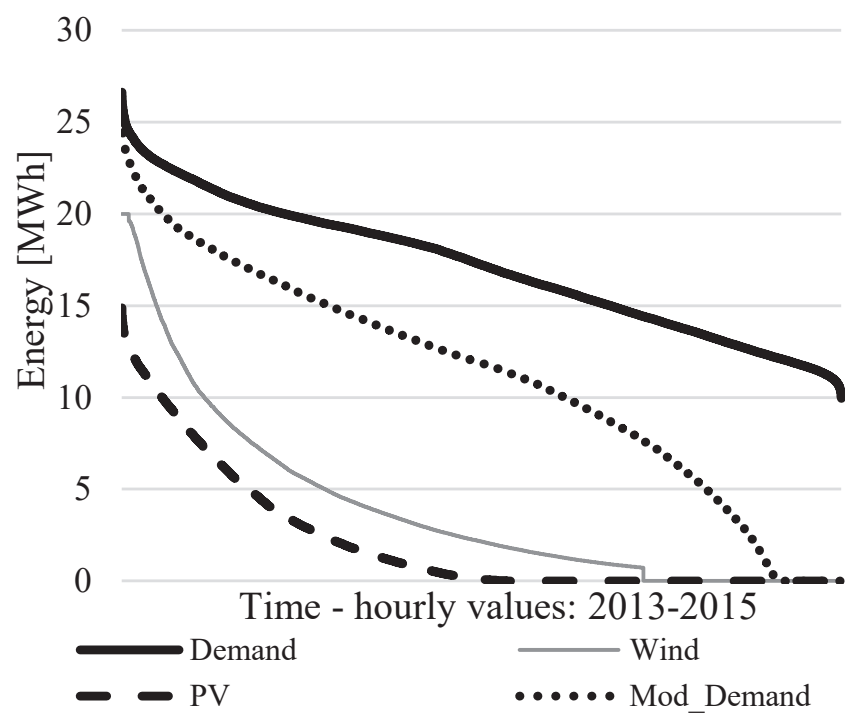

Fig. 2. Ordered observed energy volumes for exemplar PV-WT-PSH having $20 \mathrm{MWs}$ installed both in PV and WT, 13 MWs in PSH pumps and $113 \mathrm{MWh}$ of storing capacity of the upper reservoir cost $[€ / \mathrm{kWh}]$ will not exceed the present energy price from the energy system by $\delta-1$. The next indirect constraint was the maximal pumping capacity of the PSH - we describe this as an indirect constraint because potentially the total volume of energy in PV and WT can exceed the pumping potential of the PSH. This is because some portion of energy generated by PV and WT (usually the majority) will always be used to cover current demand. Therefore, potential surpluses to be stored will be significantly smaller than the maximal generating capacity of both PV and WT sources. Fig. 2 visualizes this situation for a hypothetical configuration of the PV-WT-PSH hybrid. The solid black line is energy demand sorted from the highest to lowest observed values - the same procedure has been applied to all three remaining time series. This shows the structure of energy demand and generation, such as the occurrence of extreme values. Please note for example PV energy yield, which rarely reaches $75 \%$ of nominal capacity and over $80 \%$ of records are even below $25 \%$ of the 20 -MWh maximal output. The most evident impact of implementing this hybrid energy source can be seen by comparing the initial and modified (Mod_Demand) energy demand curves. For the considered PV-WT-PSH characteristic, RES covered $35 \%$ of the $150-\mathrm{GWh}$ annual energy demand. The hybrid source significantly lowered the average demand covered from the NPS (dotted line) and even led to situations where that value was zero.

Analysis of the results presented in Table 4 reveals that feasible solutions have not been found for a total of 18 scenarios which assumed that the new energy cost resulting from the introduction of the PV-WT-PSH energy source will not be higher than the current price in the energy sector. This translates into a situation in which introducing RES (in the form of the considered hybrid source) into the reality described by the parameters used in this model leads to an increase in direct energy cost. However, one must bear in mind that this is mainly due to the prohibitive costs of energy storage, which in all remaining scenarios ranged from $30 \%$ to $58 \%$ of the energy delivered cost. What is more, using PSH with the parameters predetermined earlier, and assuming that the total cost of energy cannot increase by more than a certain percentage, left a very small margin for the introduction of PV and WT energy sources. This becomes evident when one compares the scenarios with various accepted increases in energy cost and the same parameters of PSH. When a relatively small upper reservoir was considered ( $6 \mathrm{~h}$ of energy storage, $V^{M}=113 \mathrm{MWh}$ ) its maximal capacity was reached in almost all scenarios. In other instances those values start to vary depending on the imposed constraint in the form of a maximal acceptable cost increase. Thus, for an energy cost specific for households and a storage capacity of $227 \mathrm{MWh}$, the maximal volume of energy stored in the upper reservoir reached $55 \%$ for $\delta=1.25,88 \%$ for $\delta=1.5$ and $98 \%$ for $\delta=1.75$ while considering all possible pumping/generating capacities of the PSH (which seemed not to have an impact on the obtained results). A similar situation arose for industrial energy prices, but the impact of PSH cost on maximal capacity installed in PV and WT was also visible for the smallest reservoir (for which the maximal storing capacity was reached only when a $50 \%$ or $75 \%$ price increase was allowed). 
Table 4

Optimization results, where: $\delta$ - acceptable energy cost increase, $\mathrm{P} \& \mathrm{G}$ - pumping and generating capacity of the $\mathrm{PSH}, \mathrm{P}^{\mathrm{PV}}-$ capacity installed in $\mathrm{PVs}, \mathrm{P}^{\mathrm{WT}}$ - capacity installed in wind turbines, V_Avg - average upper reservoir occupancy, V_Max - maximal upper reservoir occupancy.

\begin{tabular}{|c|c|c|c|c|c|c|c|c|c|c|c|c|c|}
\hline \multicolumn{4}{|c|}{ Scenario } & \multicolumn{2}{|c|}{ Capacity } & \multicolumn{2}{|c|}{ Statistics } & \multicolumn{2}{|c|}{ PSH } & \multicolumn{4}{|c|}{ Cost contribution } \\
\hline$E C$ & $\delta$ & $\begin{array}{c}V^{M} \\
{[\mathbf{M W h}]}\end{array}$ & $\begin{array}{c}P \& G \\
{[\mathrm{MWh}]}\end{array}$ & $\begin{array}{c}P^{P V} \\
{[\mathrm{MW}]}\end{array}$ & $\begin{array}{c}P^{W T} \\
{[\mathrm{MW}]}\end{array}$ & $\begin{array}{l}\text { RES } \\
\text { Share }\end{array}$ & $\begin{array}{c}\text { Emissions } \\
\qquad E E I^{E S}\end{array}$ & $\begin{array}{c}V_{-} A v g \\
{[\mathbf{M W h}]}\end{array}$ & $\begin{array}{l}V_{-} \operatorname{Max} \\
{[\mathbf{M W h}]}\end{array}$ & $P V$ & $W T$ & PSH & $E S$ \\
\hline \multirow{27}{*}{ 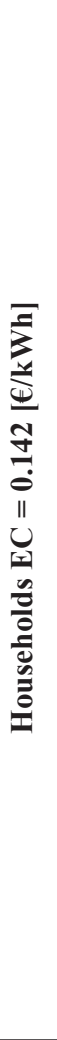 } & 1.25 & 455.5 & 52 & 22 & 20 & $36.2 \%$ & $65.2 \%$ & 2.05 & 117.92 & $7.5 \%$ & $9.9 \%$ & $31.2 \%$ & $51.4 \%$ \\
\hline & 1.25 & 455.5 & 26 & 23 & 21 & $37.9 \%$ & $63.5 \%$ & 2.90 & 129.69 & $7.7 \%$ & $10.3 \%$ & $32.2 \%$ & $49.9 \%$ \\
\hline & 1.25 & 455.5 & 13 & 24 & 21 & $38.5 \%$ & $62.9 \%$ & 3.13 & 121.35 & $8.0 \%$ & $10.2 \%$ & $32.5 \%$ & $49.3 \%$ \\
\hline & 1.25 & 227.75 & 52 & 24 & 19 & $36.3 \%$ & $65.0 \%$ & 1.86 & 119.60 & $8.1 \%$ & $9.4 \%$ & $31.1 \%$ & $51.3 \%$ \\
\hline & 1.25 & 227.75 & 26 & 25 & 20 & $38.0 \%$ & $63.3 \%$ & 2.60 & 131.44 & $8.3 \%$ & $9.8 \%$ & $32.1 \%$ & $49.8 \%$ \\
\hline & 1.25 & 227.75 & 13 & 24 & 21 & $38.5 \%$ & $62.8 \%$ & 3.13 & 121.35 & $8.0 \%$ & $10.3 \%$ & $32.3 \%$ & $49.5 \%$ \\
\hline & 1.25 & 113.875 & 52 & 24 & 19 & $36.3 \%$ & $64.9 \%$ & 1.85 & 113.87 & $8.1 \%$ & $9.5 \%$ & $31.0 \%$ & $51.4 \%$ \\
\hline & 1.25 & 113.875 & 26 & 25 & 20 & $38.0 \%$ & $63.2 \%$ & 2.59 & 113.87 & $8.4 \%$ & $9.8 \%$ & $31.9 \%$ & $49.9 \%$ \\
\hline & $\underline{1.25}$ & $\underline{113.875}$ & $\underline{13}$ & $\underline{24}$ & $\underline{21}$ & $\underline{38.5 \%}$ & $\underline{62.7 \%}$ & $\underline{3.13}$ & $\underline{113.87}$ & $\underline{8.1 \%}$ & $\underline{10.3 \%}$ & $\underline{32.1 \%}$ & $\underline{49.5 \%}$ \\
\hline & 1.5 & 455.5 & 52 & 24 & 24 & $41.7 \%$ & $59.8 \%$ & 7.02 & 252.61 & $6.6 \%$ & $9.5 \%$ & $45.1 \%$ & $38.9 \%$ \\
\hline & 1.5 & 455.5 & 26 & 25 & 24 & $41.7 \%$ & $59.8 \%$ & 7.02 & 252.61 & $6.6 \%$ & $9.5 \%$ & $45.1 \%$ & $38.9 \%$ \\
\hline & $\underline{1.5}$ & $\underline{455.5}$ & $\underline{13}$ & $\underline{24}$ & $\underline{25}$ & $\underline{42.8 \%}$ & $\underline{58.7 \%}$ & $\underline{9.14}$ & $\underline{314.32}$ & $\underline{6.6 \%}$ & $\underline{9.8 \%}$ & $\underline{45.1 \%}$ & $38.5 \%$ \\
\hline & 1.5 & 227.75 & 52 & 25 & 23 & $41.2 \%$ & $60.1 \%$ & 5.62 & 201.61 & $7.0 \%$ & $9.3 \%$ & $43.5 \%$ & $40.1 \%$ \\
\hline & 1.5 & 227.75 & 26 & 25 & 23 & $41.2 \%$ & $60.1 \%$ & 5.62 & 201.61 & $7.3 \%$ & $9.8 \%$ & $41.0 \%$ & $41.9 \%$ \\
\hline & 1.5 & 227.75 & 13 & 25 & 23 & $41.3 \%$ & $60.1 \%$ & 5.68 & 201.61 & $7.4 \%$ & $9.9 \%$ & $40.2 \%$ & $42.5 \%$ \\
\hline & 1.5 & 113.875 & 52 & 25 & 20 & $38.0 \%$ & $63.2 \%$ & 2.59 & 113.85 & $8.0 \%$ & $9.4 \%$ & $35.1 \%$ & $47.6 \%$ \\
\hline & 1.5 & 113.875 & 26 & 25 & 20 & $38.0 \%$ & $63.2 \%$ & 2.59 & 113.85 & $8.4 \%$ & $9.8 \%$ & $31.9 \%$ & $49.9 \%$ \\
\hline & 1.5 & 113.875 & 13 & 25 & 21 & $39.1 \%$ & $62.1 \%$ & 3.34 & 113.85 & $8.2 \%$ & $10.0 \%$ & $33.8 \%$ & $48.0 \%$ \\
\hline & 1.75 & 455.5 & 52 & 29 & 25 & $45.7 \%$ & $56.0 \%$ & 11.06 & 320.18 & $6.5 \%$ & $8.2 \%$ & $54.1 \%$ & $31.1 \%$ \\
\hline & 1.75 & 455.5 & 26 & 30 & 25 & $46.2 \%$ & $55.4 \%$ & 11.55 & 321.34 & $6.8 \%$ & $8.3 \%$ & $53.9 \%$ & $31.1 \%$ \\
\hline & 1.75 & 455.5 & 13 & 32 & 24 & $46.3 \%$ & $55.4 \%$ & 10.00 & 262.92 & $7.2 \%$ & $8.0 \%$ & $53.7 \%$ & $31.1 \%$ \\
\hline & 1.75 & 227.75 & 52 & 32 & 23 & $45.3 \%$ & $56.3 \%$ & 8.28 & 223.50 & $7.1 \%$ & $7.7 \%$ & $53.7 \%$ & $31.5 \%$ \\
\hline & 1.75 & 227.75 & 26 & 33 & 23 & $45.8 \%$ & $55.7 \%$ & 8.77 & 227.75 & $7.4 \%$ & $7.7 \%$ & $53.5 \%$ & $31.4 \%$ \\
\hline & $\underline{1.75}$ & $\underline{227.75}$ & $\underline{13}$ & $\underline{34}$ & $\underline{23}$ & $\underline{46.4 \%}$ & $\underline{55.2 \%}$ & $\underline{8.97}$ & $\underline{216.74}$ & $\underline{7.4 \%}$ & $\underline{7.6 \%}$ & $\underline{54.3 \%}$ & $30.6 \%$ \\
\hline & 1.75 & 113.875 & 52 & 31 & 17 & $38.2 \%$ & $63.2 \%$ & 2.57 & 113.87 & $9.1 \%$ & $7.6 \%$ & $38.4 \%$ & $44.9 \%$ \\
\hline & 1.75 & 113.875 & 26 & 31 & 17 & $38.2 \%$ & $63.2 \%$ & 2.57 & 113.87 & $9.5 \%$ & $7.9 \%$ & $35.6 \%$ & $47.0 \%$ \\
\hline & 1.75 & 113.875 & 13 & 34 & 19 & $42.2 \%$ & $59.3 \%$ & 4.57 & 113.87 & $8.7 \%$ & $7.5 \%$ & $45.6 \%$ & $38.2 \%$ \\
\hline \multirow{27}{*}{ 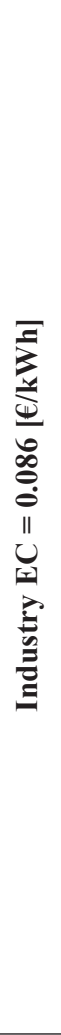 } & 1.25 & 455.5 & 52 & 15 & 14 & $25.3 \%$ & $75.8 \%$ & 0.09 & 45.50 & $8.7 \%$ & $11.9 \%$ & $19.6 \%$ & $59.9 \%$ \\
\hline & 1.25 & 455.5 & 26 & 21 & 15 & $30.1 \%$ & $71.2 \%$ & 0.43 & 77.74 & $12.0 \%$ & $12.6 \%$ & $19.3 \%$ & $56.1 \%$ \\
\hline & 1.25 & 455.5 & 13 & 23 & 15 & $31.3 \%$ & $70.1 \%$ & 0.60 & 86.43 & $13.0 \%$ & $12.6 \%$ & $19.3 \%$ & $55.1 \%$ \\
\hline & 1.25 & 227.75 & 52 & 16 & 14 & $25.9 \%$ & $75.1 \%$ & 0.11 & 49.59 & $9.2 \%$ & $11.8 \%$ & $19.6 \%$ & $59.3 \%$ \\
\hline & 1.25 & 227.75 & 26 & 21 & 15 & $30.1 \%$ & $71.1 \%$ & 0.43 & 77.74 & $12.0 \%$ & $12.7 \%$ & $18.9 \%$ & $56.3 \%$ \\
\hline & 1.25 & 227.75 & 13 & 20 & 17 & $31.7 \%$ & $69.4 \%$ & 0.69 & 87.12 & $11.4 \%$ & $14.2 \%$ & $19.6 \%$ & $54.8 \%$ \\
\hline & 1.25 & 113.875 & 52 & 16 & 14 & $25.9 \%$ & $75.0 \%$ & 0.11 & 49.59 & $9.3 \%$ & $11.9 \%$ & $19.4 \%$ & $59.5 \%$ \\
\hline & 1.25 & 113.875 & 26 & 18 & 17 & $30.5 \%$ & $70.5 \%$ & 0.53 & 78.11 & $10.3 \%$ & $14.2 \%$ & $19.8 \%$ & $55.7 \%$ \\
\hline & $\underline{1.25}$ & $\underline{113.875}$ & $\underline{13}$ & $\underline{20}$ & $\underline{17}$ & $\underline{31.7 \%}$ & $\underline{69.3 \%}$ & $\underline{0.69}$ & $\underline{87.12}$ & $\underline{11.4 \%}$ & $14.2 \%$ & $\underline{19.4 \%}$ & $54.9 \%$ \\
\hline & 1.5 & 455.5 & 52 & 23 & 17 & $33.5 \%$ & $67.9 \%$ & 0.99 & 100.65 & $10.9 \%$ & $11.9 \%$ & $32.4 \%$ & $44.9 \%$ \\
\hline & 1.5 & 455.5 & 26 & 23 & 19 & $35.7 \%$ & $65.7 \%$ & 1.69 & 115.17 & $10.7 \%$ & $12.9 \%$ & $33.5 \%$ & $42.9 \%$ \\
\hline & 1.5 & 455.5 & 13 & 24 & 19 & $36.4 \%$ & $65.1 \%$ & 1.87 & 108.57 & $11.1 \%$ & $12.9 \%$ & $33.4 \%$ & $42.5 \%$ \\
\hline & 1.5 & 227.75 & 52 & 22 & 18 & $34.0 \%$ & $67.2 \%$ & 1.16 & 103.40 & $10.3 \%$ & $12.4 \%$ & $33.3 \%$ & $44.0 \%$ \\
\hline & 1.5 & 227.75 & 26 & 22 & 18 & $34.0 \%$ & $67.2 \%$ & 1.16 & 103.40 & $11.1 \%$ & $13.3 \%$ & $28.4 \%$ & $47.2 \%$ \\
\hline & 1.5 & 227.75 & 13 & 24 & 19 & $36.4 \%$ & $64.9 \%$ & 1.87 & 108.57 & $11.2 \%$ & $13.0 \%$ & $33.2 \%$ & $42.7 \%$ \\
\hline & 1.5 & 113.875 & 52 & 22 & 18 & $34.0 \%$ & $67.1 \%$ & 1.16 & 103.40 & $10.3 \%$ & $12.4 \%$ & $33.1 \%$ & $44.1 \%$ \\
\hline & 1.5 & 113.875 & 26 & 23 & 19 & $35.7 \%$ & $65.4 \%$ & 1.69 & 113.87 & $10.8 \%$ & $13.0 \%$ & $33.1 \%$ & $43.1 \%$ \\
\hline & $\underline{1.5}$ & $\underline{113.875}$ & $\underline{13}$ & $\underline{24}$ & $\underline{19}$ & $\underline{36.4 \%}$ & $\underline{64.9 \%}$ & $\underline{1.87}$ & $\underline{108.57}$ & $11.2 \%$ & $13.0 \%$ & $\underline{33.0 \%}$ & $42.8 \%$ \\
\hline & 1.75 & 455.5 & 52 & 26 & 19 & $37.5 \%$ & $64.0 \%$ & 2.24 & 128.69 & $10.3 \%$ & $11.1 \%$ & $42.5 \%$ & $36.1 \%$ \\
\hline & 1.75 & 455.5 & 26 & 25 & 21 & $39.1 \%$ & $62.4 \%$ & 3.35 & 138.71 & $9.8 \%$ & $12.0 \%$ & $43.3 \%$ & $34.9 \%$ \\
\hline & 1.75 & 455.5 & 13 & 27 & 20 & $39.2 \%$ & $62.3 \%$ & 3.07 & 116.79 & $10.6 \%$ & $11.6 \%$ & $42.6 \%$ & $35.2 \%$ \\
\hline & 1.75 & 227.75 & 52 & 23 & 21 & $37.9 \%$ & $63.4 \%$ & 2.92 & 129.70 & $9.1 \%$ & $12.1 \%$ & $43.3 \%$ & $35.6 \%$ \\
\hline & 1.75 & 227.75 & 26 & 25 & 21 & $39.1 \%$ & $62.2 \%$ & 3.35 & 138.71 & $9.8 \%$ & $12.1 \%$ & $43.1 \%$ & $35.0 \%$ \\
\hline & 1.75 & 227.75 & 13 & 24 & 22 & $39.6 \%$ & $61.7 \%$ & 4.10 & 156.73 & $9.4 \%$ & $12.5 \%$ & $43.4 \%$ & $34.6 \%$ \\
\hline & 1.75 & 113.875 & 52 & 25 & 20 & $38.0 \%$ & $63.2 \%$ & 2.60 & 113.87 & $9.8 \%$ & $11.5 \%$ & $43.2 \%$ & $35.5 \%$ \\
\hline & 1.75 & 113.875 & 26 & 29 & 18 & $38.2 \%$ & $63.2 \%$ & 2.45 & 113.87 & $11.4 \%$ & $10.6 \%$ & $41.8 \%$ & $36.1 \%$ \\
\hline & $\underline{1.75}$ & $\underline{113.875}$ & $\underline{13}$ & $\underline{26}$ & $\underline{21}$ & $\underline{39.7 \%}$ & $\underline{61.6 \%}$ & $\underline{3.58}$ & $\underline{113.88}$ & $\underline{10.1 \%}$ & $\underline{12.0 \%}$ & $\underline{43.5 \%}$ & $\underline{34.5 \%}$ \\
\hline
\end{tabular}


One should not totally blame PSH for prohibiting RES from increasing their share in covering energy demand. A more thorough analysis reveals that in scenarios with the same maximal allowed cost growth, the share of RES also picked up as upper reservoir capacity increased - for household scenarios by, on average, $2 \%, 4 \%$ and $8 \%$ for $\delta=1.25, \delta=1.5$ and $\delta=1.75$, respectively. The mean share of RES in household scenarios ranged from $36 \%$ to $46 \%$ and enabled an emissions decrease of $35 \%$ and $45 \%$, respectively. Naturally, one would like to curtail emissions in a manner which incurs the lowest possible increase in total cost. For households this can be done by a PV-TW-PSH hybrid energy source with the following parameters: $24 \mathrm{MWs}$ in PV, $21 \mathrm{MWs}$ in WT, storage capacity of $113 \mathrm{MWh}$, and pumping/generating capacity of $13 \mathrm{MWh}$. Such a source will cut emissions by $37.3 \%$ and the share of RES in covering energy demand will increase to $38.5 \%$. In consequence, each MWh used by consumers will lead to an emission of $501 \mathrm{~kg}$ of $\mathrm{CO}_{2}$ instead of $810 \mathrm{~kg}$. However, the cost will increase by $25 \%$.

The situation is a little more complicated for industrial energy prices, where the usually higher energy cost from RES and the previously mentioned impact of PSH on the allowed installed capacity in PVs and WTs caused the RES share to be on average $10 \%$ lower than household scenarios. Naturally, the possible curtailment of emissions was also much smaller and ranged from $24 \%$ to $38 \%$. In general, for all possible variants of PSH characteristics and an allowable energy cost increase of $25 \%$, mean $\mathrm{CO}_{2}$ emissions amounted to $28 \%$. This is especially important because the industry sector is usually very energy intensive and itself generates significant emissions, and using electricity from high-emission energy sources leads to additional indirect emissions. The concept of using renewable energy has already been described for two industrial processes in Poland in $[53,54]$, which revealed that the character of electro-refinement and chloro-alakli processes are suitable for being powered by intermittent/variable renewable energy sources.

What is very interesting is the share of individual energy sources (including PSH) in the total cost of energy. In all considered scenarios PV on average covered $15 \%$ of the energy demand whilst contributing to $9.1 \%$ of the final energy cost. The mean share of wind generation in covering energy demand was $23 \%$, incurring $10.3 \%$ of energy cost. Please note that by increasing the maximal energy cost by $25 \%$ the total capacity installed in $\mathrm{PV}$ and WT increases by only $5 \mathrm{MW}$ on average, but the cost of storing energy increased with this by $10 \%$. This is due to the fact that, with PSH, not only should one consider upfront investments (construction of the PSH) but also the costs of its operation. The increasing role of energy storage is clear if one compares the mean volume of energy stored in the upper reservoir for various scenarios. Figure 3 depicts the mean hourly usage of the PSH upper reservoir and energy yield from PV and WT for the scenario: $\delta=1.75, \mathrm{EC}=0.142 € / \mathrm{kWh}^{\mathrm{M}} \mathrm{V}^{\mathrm{M}}=113 \mathrm{MWh}$, $\mathrm{P} / \mathrm{G}=13 \mathrm{MWh}, \mathrm{P}^{\mathrm{PV}}=34 \mathrm{MW}$, and $\mathrm{P}^{\mathrm{WT}}=19 \mathrm{MW}$.

4.1. Cost sensitivity analysis. In order to investigate the impact of varying energy costs of energy derived from PV and wind turbines a cost sensitivity analysis was performed assuming

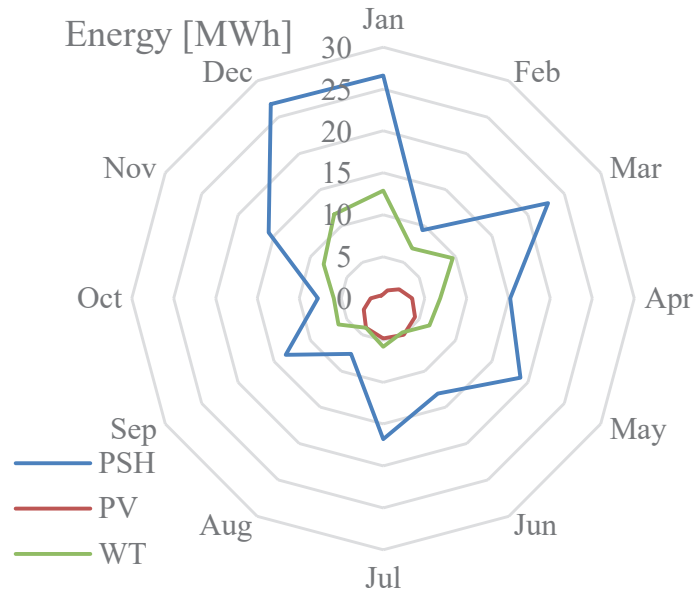

Fig. 3. Mean hourly energy storage/generation over the year

a normal distribution of the values presented in Table 3. For the sensitivity analysis, the scenarios which allowed the lowest emissions to be achieved were selected from each cost constraint case ( $\delta=1.25$, etc.). If two scenarios exhibited the same value of the objective function, the scenario with the lowest upper reservoir storage capacity was selected; if that criterion was not decisive, the one with the smallest pumping/generating capacity was chosen. The selected scenarios are those underlined in Table 2 and the results of their cost sensitivity analysis is depicted in Fig. 3. They show that the impact of the Levelized Cost of Electricity which can be obstained from PV or WT has a rather moderate impact on cost increase. The analysis of the first considered scenario (H_1), where RES covered $38.5 \%$ of the energy demand, shows that the impact of varying energy costs from PV and WT may result in cost deviating by $4 \%$ from the maximal assumed increase of $25 \%$. In the third scenario (H_3), with RES share amounting to $46.4 \%$, the expected cost may increase by values ranging from $70 \%$ to $80 \%$. In scenarios which assumed common energy prices for industry the share of RES was smaller but the impact on overall energy prices was significantly higher. This means that in the first scenario, where RES covered $31.7 \%$ of demand, the new energy price

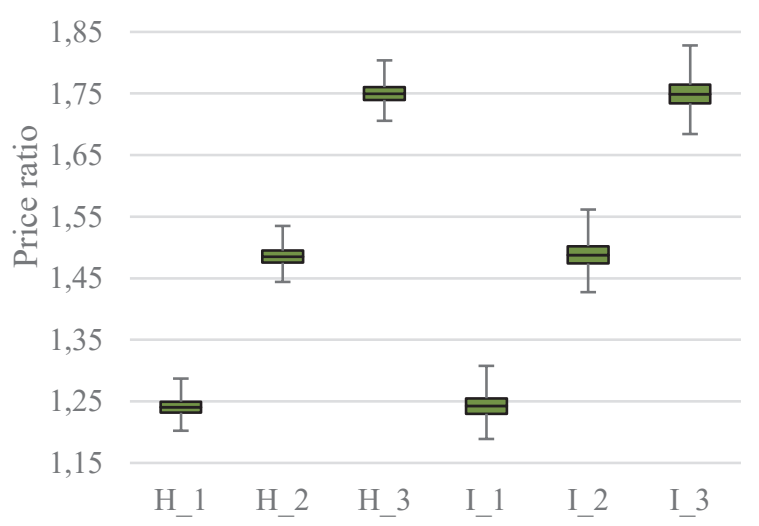

Fig. 3. Cost sensitivity analysis. Key: $\mathrm{H}$ - households, I - industry, $1,2,3$ - sequence of selected scenarios from Table 2 
can range from $118 \%$ to $130 \%$ of the present cost of the energy delivered from the NPS. With an increasing share of variable generation this range increases to $13.5 \%$ and $14 . \%$ respectively in scenarios I_2 and I_3.

4.2. Impact on demand curve. Introducing non-dispatchable energy sources to the energy system causes additional variation/ disruptions on the energy market. In the investigated models the assumption was made that the proposed PV-WT-PSH hybrid should opearate in such a manner than no energy surpluses will occur. This is an important issue, because generating energy surpluses causes a situation in which an energy system (such as Polish one) dominated by coal powered power plants and possessing limited energy storage capabilities [55] will have to ramp up and down the operation of conventional power plants. This will come at an additional cost and will be done in order to manage randomly occurring energy surpluses from PV and WT. However, even if the energy surpluses do not occur, operation of PV-WT-PSH is determined by the variability of PV and WT sources. Therefore, the share of the demand covered from hybrid energy sources will also vary. In order to assess that impact, three statistical parameters (mean - AVG, standard deviation - STD and coefficient of variation - CV) has been calculated for original (denominated by Zero in Table 4) and modified demand time series in the scenarios investigated in the cost sensitivity analysis. The obtained results are presented in Table 4, with values given in their respective units; MWh for AVG and STD and \% for CV.

Analysis of the values presented in Table 4 indicates that the introduction of a non-dispatchable energy source leads to increasing variability in the demand curve. In higher penetration of VRES in the energy market this might seriously impede the accuracy of energy demand forecasts. That is because they do not consider demand to be impacted by varying energy yield from local energy sources. In the investigated scenarios the coefficient of variation (calculated as a ratio of the mean to the standard deviation) increased, and was two to four times greater than in the benchmark scenario (Zero) which did not consider renewable generation. The smallest increase was observed in scenario I_1 in which the share of RES in covering the energy demand was also the lowest among the considered scenarios.

Table 4

Values of parameters used

\begin{tabular}{|l|r|r|r|r|r|r|r|}
\cline { 2 - 8 } \multicolumn{1}{c|}{} & Zero & H_1 & \multicolumn{1}{c|}{ H_2 } & \multicolumn{1}{c|}{ H_3 } & \multicolumn{1}{c|}{ I_1 } & \multicolumn{1}{c|}{ I_2 } & \multicolumn{1}{c|}{ I_3 } \\
\hline AVG & 17.1 & 10.5 & 9.8 & 9.2 & 11.7 & 10.9 & 10.3 \\
\hline STD & 3.5 & 6.4 & 6.7 & 7.0 & 5.8 & 6.3 & 6.5 \\
\hline CV & 20.6 & 61.6 & 68.6 & 76.2 & 49.5 & 57.5 & 63.4 \\
\hline
\end{tabular}

\section{Conclusions}

In this paper, we addressed the concept of hybrid energy sources utilizing the energy of solar radiation and wind speed. Due to the intermittent nature of both sources the mentioned energy source was equipped with an energy storage device in the form of pumped storage-hydroelectricity, which is known to be the only mature bulk energy storage technology available today. A mixed integer mathematical model was formulated in order to simulate the behavior of a PV-WT-PSH hybrid, as well as to optimize its parameters. The optimization procedure was conducted with an objective function to minimize the environmental impact whilst not exceeding the imposed constraint. The results generated revealed that despite the major impact of PSH on energy cost it is still possible to significantly increase the share of renewable energy generation in covering the energy demand. Naturally, the current costs of renewable energy, as well as the selected sites for simulation led to an increase in energy costs. For wind generation, location is especially meaningful because it always has an impact on the hybrid energy source's cost effectiveness.) In general, it is possible to cover almost $40 \%$ of non-industrial consumer energy demand by means of a PV-WT-PSH hybrid whilst not increasing the energy cost by more than $25 \%$, whereas for industrial demand over $25 \%$ to $30 \%$ can be covered depending on the scenario; it is important to note that those results are valid when the energy is directly transferred to the consumers via a relatively short transmission line which does not entail additional costs.

As for now, the presented mathematical formulation can be easily transformed into a multi-objective optimization problem. Therefore, in the future we would like to further investigate the concept of PV-WT-PSH operation as part of the national energy sector, considering e.g. the cost of $\mathrm{CO}_{2}$ emissions and the potential benefits of selling green energy on the energy market. However, we strongly believe that the introduction of VRES should come without additional disruption to the operation of the energy market - meaning that to the maximal extent new renewable energy sources should cover the energy demand of a given group of consumers without "sending" the energy to the national grid.

Acknowledgements. "J. Jurasz would like to express his gratitude towards Prof. Tadeusz Sawik who has introduced him to the area of mathematical modeling. The authors are grateful to two anonymous reviewers and editors for reading the manuscript very carefully and providing constructive comments which helped us to improve the quality of our paper."

\section{REFERENCES}

[1] B. Igliński, G. Piechota, and R. Buczkowski, "Development of biomass in Polish energy sector: an overview", Clean Technologies and Environmental Policy 17(2), 317-329

[2] B. Igliński, A. Iglińska, G. Koziński, M. Skrzatek, and R. Buczkowski, "Wind energy in Poland-History, current state, surveys, Renewable Energy Sources Act, SWOT analysis", Renewable and Sustainable Energy Reviews 64, (2016).

[3] J.H. Seinfeld and S.N. Pandis, Atmospheric Chemistry and Physics: From Air pollution to Climate Change, John Wiley \& Sons, 2016.

[4] J. Twidell and T. Weir, Renewable Energy Resources, Routledge, 2015. 
[5] M.A. Green, K. Emery, Y. Hishikawa, W. Warta, and E.D. Dunlop, Solar cell efficiency tables (Version 45), Progress in photovoltaics: research and applications 23(1), 1-9 (2015).

[6] B. Liu, M. Holmbom, A. Segerstedt, and W. Chen, "Effects of carbon emission regulations on remanufacturing decisions with limited information of demand distribution", International Journal of Production Research 53(2), 532-548 (2015).

[7] T. Hong, P. Pinson, S. Fan, H. Zareipour, A. Troccoli, and R.J. Hyndman, "Probabilistic energy forecasting: Global energy forecasting competition 2014 and beyond", International Journal of Forecasting 32(3), 896-913 (2016).

[8] T. Kaur, S. Kumar, and R. Segal, "Application of artificial neural network for short term wind speed forecasting", Biennial International Conference on Power and Energy Systems: Towards Sustainable Energy (PESTSE), 1-5 (2016).

[9] O.B. Shukur and M.H. Lee, "Daily wind speed forecasting through hybrid KF-ANN model based on ARIMA", Renewable Energy 76, 637-647 (2015).

[10] J.R. Trapero, N. Kourentzes, and A. Martin, "Short-term solar irradiation forecasting based on dynamic harmonic regression", Energy 84, 289-295 (2015).

[11] A. Ahmad, T.N. Anderson, and T.T. Lie, "Hourly global solar irradiation forecasting for New Zealand", Solar Energy 122, 1398-1408 (2015).

[12] M.M. Miglietta, T. Huld, and F. Monforti-Ferrario, "Local complementarity of wind and solar energy resources over Europe: an assessment study from a meteorological perspective", Journal of Applied Meteorology and Climatology (2016).

[13] A.R. Silva, F.M. Pimenta, A.T. Assireu, Spyrides, and M.H.C., "Complementarity of Brazil's hydro and offshore wind power", Renewable and Sustainable Energy Reviews 56, 413-427 (2016).

[14] J. Jurasz and B. Ciapała, "Integrating photovoltaics into energy systems by using a run-off-river power plant with pondage to smooth energy exchange with the power grid", Applied Energy 198, 21-35 (2017).

[15] V. Khare, S. Nema, and P. Baredar, "Solar-wind hybrid renewable energy system: A review", Renewable and Sustainable Energy Reviews 58, 23-33 (2016).

[16] F. Díaz-González, A. Sumper, O. Gomis-Bellmunt, and R. Villafáfila-Robles, "A review of energy storage technologies for wind power applications", Renewable and Sustainable Energy Reviews 16(4), 2154-2171 (2012)

[17] A. Evans, V. Strezov, and T. J. Evans, "Assessment of utility energy storage options for increased renewable energy penetration", Renewable and Sustainable Energy Reviews 16(6), 4141-4147 (2012).

[18] A. Kies, B. U. Schyska, and L. von Bremen, „The Demand Side Management Potential to Balance a Highly Renewable European Power System", Energies 9(11), 955 (2016).

[19] M.Z. Jacobson and M.A. Delucchi, "Providing all global energy with wind, water, and solar power, Part I: Technologies, energy resources, quantities and areas of infrastructure, and materials", Energy Policy 39(3), 1154-1169 (2011).

[20] M.A. Delucchi and M.Z. Jacobson, "Providing all global energy with wind, water, and solar power, Part II: Reliability, system and transmission costs, and policies", Energy policy 39(3), 1170-1190 (2011).

[21] J. Jurasz and A. Piasecki, "Evaluation of the complementarity of wind energy resources, solar radiation and flowing water-a case study of Piła”, Acta Energetica (2016).
[22] J. Jurasz, A. Piasecki, and M. Wdowikowski, "Assessing temporal complementarity of solar, wind and hydrokinetic energy", E3S Web of Conferences Vol. 10, p. 00032 (2016).

[23] C.E. Hoicka and I.H. Rowlands, "Solar and wind resource complementarity: Advancing options for renewable electricity integration in Ontario, Canada", Renewable Energy 36(1), 97-107 (2011).

[24] Y. Li, V.G. Agelidis, and Y. Shrivastava, "Wind-solar resource complementarity and its combined correlation with electricity load demand", 4th IEEE Conference on Industrial Electronics and Applications, 3623-3628 (2009).

[25] J.K. Kaldellis, M. Kapsali, and K.A. Kavadias, "Energy balance analysis of wind-based pumped hydro storage systems in remote island electrical networks", Applied Energy 87(8), 2427-2437 (2010).

[26] M. Kapsali, J.S. Anagnostopoulos, and J.K. Kaldellis, "Wind powered pumped-hydro storage systems for remote islands: a complete sensitivity analysis based on economic perspectives", Applied Energy 99, 430-444 (2012).

[27] M. Kapsali and J.K. Kaldellis, "Combining hydro and variable wind power generation by means of pumped-storage under economically viable terms", Applied Energy 87(11), 3475-3485 (2010).

[28] D.A. Katsaprakakis, D.G. Christakis, K. Pavlopoylos, S. Stamataki, I. Dimitrelou, I. Stefanakis, and P. Spanos, "Introduction of a wind powered pumped storage system in the isolated insular power system of Karpathos-Kasos”, Applied Energy 97, 38-48 (2012).

[29] J. Jurasz, J. Mikulik, and A. Piasecki, "Use of pumped-storage hydroelectricity to compensate for the inherent variability of wind energy", 8th Eastern European Young Water Professionals Conference, 758-765 (2016).

[30] J. Jurasz and J. Mikulik, "Scheduling opearation of wind powered pumped-storage hydroelectricity", 13th International Conference on Industrial Logistics, 74-83 (2016).

[31] M.A. Hessami and D.R. Bowly, "Economic feasibility and optimisation of an energy storage system for Portland Wind Farm (Victoria, Australia)", Applied Energy 88(8), 2755-2763 (2011).

[32] K. Hedegaard and P. Meibom, "Wind power impacts and electricity storage-A time scale perspective", Renewable Energy 37(1), 318-324 (2012).

[33] T. Ma, H. Yang, L. Lu, and J. Peng, "Pumped storage-based standalone photovoltaic power generation system: modeling and techno-economic optimization", Applied Energy 137, 649-659 (2015).

[34] T. Ma, H. Yang, L. Lu, and J. Peng, "Optimal design of an autonomous solar-wind-pumped storage power supply system", $A p$ plied Energy 160, 728-736 (2015).

[35] T. Ma, H. Yang, and L. Lu, (2014), "Feasibility study and economic analysis of pumped hydro storage and battery storage for a renewable energy powered island", Energy Conversion and Management 79, 387-397 (2014).

[36] D.A. Katsaprakakis, "Hybrid power plants in non-interconnected insular systems", Applied Energy 164, 268-283 (2016).

[37] J. Jurasz and J. Mikulik, "Investigating theoretical PV energy generation patterns with their relation to the power load curve in Poland", International Journal of Photoenergy, (2016).

[38] J. Jurasz, M. Krzywda, and J. Mikulik, "How might residential PV change the energy demand curve in Poland", E3S Web of Conferences Vol. 10, p. 00059 (2016).

[39] J. Jurasz, J. Mikulik, and A. Piasecki, "The Influence of temperature variability on electrical energy demand in Poland in the years 2002-2015" (in Polish), Przeglad Elektrotechniczny (Electrical Review) 92, 257-261 (2016). 
[40] A. Steiner, C. Köhler, I. Metzinger, A. Braun, M. Zirkelbach, D. Ernst, and B. Ritter, "Critical weather situations for renewable energies-Part A: Cyclone detection for wind power", Renewable Energy 101, 41-50 (2017).

[41] C. Köhler, A. Steiner, Y.M. Saint-Drenan, D. Ernst, A. Bergmann-Dick, M. Zirkelbach, and B. Ritter, "Critical weather situations for renewable energies-Part B: Low stratus risk for solar power", Renewable Energy 101, 794-803 (2017).

[42] http://www.eea.europa.eu/data-and-maps/figures/co2-electricity-g-per-kwh/co2-per-electricity-kwh-fig-1 2010 qa.xls

[43] V.M. Fthenakis and H.C. Kim, "Photovoltaics: Life-cycle analyses", Solar Energy 85(8), 1609-1628 (2011).

[44] S.L. Dolan and G.A. Heath, "Life cycle greenhouse gas emissions of utility-scale wind power", Journal of Industrial Ecology 16(s1), S136-S154 (2012).

[45] K. Flury and R. Frischknecht, "Life cycle inventories of hydroelectric power generation", ESU-Services, Fair Consulting in Sustainability, commissioned by Oko-Institute eV, 1-51 (2012).

[46] http://ec.europa.eu/eurostat/statisticsexplained/index.php/Energy_price_statistics
[47] C. Kost, J.N. Mayer, J. Thomsen, N. Hartmann, C. Senkpiel, S. Philipps, and T. Schlegl, "Levelized cost of electricity renewable energy technologies", Fraunhofer Institute for Solar Energy Systems ISE (2013).

[48] S. Sundararagavan and E. Baker, "Evaluating energy storage technologies for wind power integration”, Solar Energy 86 (9), 2707-2717 (2012).

[49] G.L. Kyriakopoulos and G. Arabatzis, "Electrical energy storage systems in electricity generation: energy policies, innovative technologies, and regulatory regimes", Renewable and Sustainable Energy Reviews 56, 1044-1067 (2016).

[50] http://www.gmes-atmosphere.eu/

[51] https://gs6101-gmao.gsfc.nasa.gov/reanalysis/MERRA-2/

[52] http://www.innogystoenoperator.pl/web/cms/pl/1638146/dladomu/

[53] T. Głąb, A. Godela, M. Myga-Nowak, J. Jurasz, and J. Boratyński "Perpective of use of sun and wind energy in the chlor-alkali industry", Przeglad Naukowo-Metodyczny (Science-Methodical Review) 1, 1180-1199 (2016). 